\title{
O SARESP E A AVALIAÇÃO INSTITUCIONAL: POSSIBILIDADES PARA O ENFRENTAMENTO DA APRENDIZAGEM NOS ANOS FINAIS DO ENSINO FUNDAMENTAL DE QUATRO ESCOLAS PÚBLICAS ESTADUAIS
}

\author{
Claudia Pereira de Pádua Sabia
}

Universidade Estadual Paulista - UNESP, Departamento de Administração e Supervisão Escolar - DASE, Marília, SP. Email: fsabia@uol.com.br.

\section{RESUMO}

O Sistema de Avaliação do Rendimento Escolar de São Paulo - SARESP foi criado em 1996 pela Resolução SE $n^{\circ} 27$ com o objetivo de servir de referência para elaboração de políticas pela Secretaria Estadual, reorientar a proposta pedagógica das escolas e utilizar os resultados para o planejamento pedagógico. O objetivo deste estudo foi identificar as características desta política pública estadual, analisar os resultados do SARESP de quatro escolas públicas estaduais e a articulação necessária com a avaliação institucional. A metodologia utilizada foi à pesquisa bibliográfica e documental (Portarias SEE e Boletins Pedagógicos do SARESP 2016). Identificamos que três escolas possuem o nível de proficiência básico e apenas uma delas, a escola 2, ficou em matemática com o nível de proficiência abaixo do básico. A partir destes resultados, de acordo com o Boletim Pedagógico os encaminhamentos pedagógicos seria a recuperação continuada para três escolas e recuperação intensiva para uma delas.

PALAVRAS-CHAVE: SARESP, Avaliação Institucional, Planejamento Pedagógico.

\section{SARESP AND INSTITUTIONAL EVALUATION: POSSIBILITIES FOR FACING LEARNING IN THE FINAL YEARS OF FUNDAMENTAL TEACHING OF FOUR STATE PUBLIC SCHOOLS}

\begin{abstract}
The System of Evaluation of the School Performance of São Paulo (SARESP) was created in 1996 by Resolution SE No. 27 with the purpose of serving as a reference for policy making by the State Secretariat, reorienting the pedagogical proposal of schools and using the results for planning pedagogical. The objective of this study was to identify the characteristics of this state public policy, analyze the results of the SARESP of four state public schools and the necessary articulation with the institutional evaluation. The methodology used was the bibliographical and documentary research (Portarias SEE and Pedagogical Bulletins of SARESP 2016). We identified that three schools have the basic proficiency level and only one of them, school 2, was in math with below proficiency level. From these results, according to the Pedagogical Bulletin, pedagogical referrals would be the continuous recovery for three schools and intensive recovery for one of them.
\end{abstract}

KEYWORDS: SARESP, Institutional Assessment, Pedagogical Planning. 


\section{INTRODUÇÃO}

Este estudo se debruça sobre a avaliação de larga escala denominada Sistema de Avaliação do Rendimento Escolar de São Paulo SARESP. De acordo com Werle (2010),

a avaliação de larga escala é um procedimento amplo e extensivo, envolvendo diferentes modalidades de avaliação, realizado por agências reconhecidas pela especialização técnica em testes e medidas, abrangendo um sistema de ensino, ou seja, todas as escolas de um determinado nível ou série deste sistema, mesmo que utilizando procedimentos amostrais, na maior parte das vezes voltada predominantemente para o foco da aprendizagem dos alunos e com a finalidade de obter resultados generalizáveis ao sistema. Portanto, a avaliação de larga escala sempre é uma avaliação externa às instituições escolares. (WERLE, 2010, p. 22).

Apesar das críticas e dos limites das avaliações de larga escala, consideramos as avaliações externas necessárias, pois, as mesmas vêm informando desde suas primeiras edições que a aprendizagem não esta ocorrendo na educação básica de nossas escolas do país. Portanto, identificamos uma evolução das pesquisas em avaliação educacional considerável nos últimos trinta anos e os estudos, bem como eventos importantes sobre este tema vêm enfatizando a necessidade de aperfeiçoamentos, redirecionamentos e informações complementares visando sua utilização para o planejamento pedagógico.

Para desenvolver este estudo, optamos por iniciar com breve retrospectiva histórica do SARESP. Na sequência abordar a avaliação institucional como uma etapa indispensável para a escola coletivamente refletir sobre seus objetivos de modo a reorientar suas ações. E finalizamos analisando os resultados dos anos finais do ensino fundamental no SARESP 2016 de quatro escolas públicas estaduais de uma cidade região oeste do oeste, disponibilizados no Boletim Pedagógico do SARESP 2016. A metodologia utilizada foi a pesquisa bibliográfica e documental.

\section{HISTÓRICO DO SARESP E SUAS CARACTERÍSTICAS}

O SARESP foi criado em 1996, por meio da Resolução SE n²7, de 29 de Março de 1996. Na época foi instituído como avaliação que visava:

Subsidiar a Secretaria de Educação na tomada de decisão quanto à política educacional; verificar o desempenho dos alunos da educação básica para fornecer informações a todas as instâncias do sistema de ensino que subsidiem a capacitação dos recursos humanos do magistério; a reorientação da proposta pedagógica das escolas, de modo a aprimorá-la; a viabilização da articulação dos resultados da avaliação com o planejamento escolar, capacitação e o estabelecimento de metas para o projeto de cada escola. (SÃO PAULO, 1996).

Bonamino e Sousa (2012) ao fazerem uma análise sobre esta avaliação, afirmam que:

os objetivos explicitados indicam que a avaliação tinha dupla orientação: servir de referência para a elaboração de políticas, por parte da Secretaria de Educação, e orientar a construção da proposta pedagógica e a elaboração do planejamento pelas escolas. (BONAMINO; SOUSA, 2012, p.380).

Quando as autoras dizem que um dos objetivos explicitados do SARESP seria o de orientar a construção pedagógica e a elaboração do planejamento pelas escolas, consideramos que a ideia era de contribuir para que os professores pudessem (re) pensar sua prática pedagógica e contribuir de forma positiva para o trabalho pedagógico desenvolvido nas salas de aulas, tendo em 
vista, que em seu bojo inicial, a avaliação mencionada tinha um caráter diagnóstico do processo de ensino e de aprendizagem.

Esse início do SARESP, que denominamos de primeira fase, compreendeu as aplicações de 1996 a 1998, apresentou características de avaliação de entrada, tendo em vista que suas aplicações ocorriam no início do ano letivo, com o intuito de oferecer informações relevantes ao desempenho dos alunos no ano anterior, ou seja, a avaliação se apresentava com um cunho de caráter diagnóstico, fornecendo informações para que os professores pudessem tomar decisões mais efetivas quanto às dificuldades apresentadas pelo aluno no ano letivo anterior.

Entretanto, após mais de uma década de aplicações consecutivas do SARESP, Bauer (2006), destaca que as ações de subsídio ao trabalho desenvolvido na sala de aula haviam sido relegadas a segundo plano em nome da ênfase ao controle do sistema por meio dos dados levantados.

Isso passou a ocorrer, especialmente no ano 2000, quando o SARESP, iniciou sua segunda fase. Nesta fase, o SARESP passou por profundas mudanças, que vão desde a ruptura da concepção de avaliação de entrada para avaliação de saída, passando por aspectos técnicos até a sua utilização como critério único para aprovação ou não nos ciclos finais (na época 4a e 8a séries).

A sua terceira fase, teve início em 2007, e traz mudanças nos rumos da avaliação. Apresenta nova metodologia ancorada aos padrões e parâmetros da avaliação SAEB, de nível nacional. Criação do índice próprio em nível estadual, o IDESP, que também se pautou no índice federal, o IDEB, associando-o a criação da Bonificação por Resultados aos professores e demais profissionais da Secretaria Estadual de Educação de São Paulo. Após estas considerações sobre as características do SARESP, discutiremos a seguir sobre a avaliação institucional como etapa necessária para a escola refletir sobre os resultados do mesmo, dentre outros aspectos.

\section{AVALIAÇÃO INSTITUCIONAL}

Entendemos que a escola deve utilizar os resultados das avaliações externas para repensar suas ações, ou seja, se autoavaliar. A autoavaliação é uma das etapas previstas na elaboração do projeto político pedagógico - PPP. O PPP deve ser construído com a participação de todos os atores da escola, proporcionando o comprometimento com seus objetivos.

Freitas et al. (2012, p.40) corrobora nossa afirmação, " [...] a referência para a avaliação institucional está no projeto político pedagógico da escola. Ele reflete compromissos do coletivo". $O$ autor ainda define o PPP,

por projeto político-pedagógico entendemos uma proposta de trabalho da escola elaborada coletivamente que orienta (e responsabiliza) a ação de seus atores, bem como formaliza demandas ao poder público e cria as condições de trabalho adequadas na escola. É portanto, um instrumento vivo e dinâmico que pauta compromissos bilaterais, onde o protagonismo é da escola. (FREITAS et al, 2012, p.40)

Destacamos também a definição de Veiga (1998). para quem

o projeto político-pedagógico explicita os fundamentos teórico-metódicos, os objetivos, o tipo de organização e as formas de implementação e avaliação da escola. As modificações que se fizerem necessárias resultam de um processo de discussão, avaliação e ajustes permanentes do projeto pedagógico. (VEIGA, 1998. p.13)

Portanto, a avaliação institucional é necessária para que os objetivos do PPP sejam reavaliados, revistos e novas ações e direcionamentos sejam implantados. É na implementação da sua avaliação institucional com a participação dos segmentos da escola que a mesma irá elencar 
os indicadores que serão considerados para identificar se os objetivos da escola estão sendo atingidos ou não, e o que fazer diante deste diagnóstico.

Cabe destacar as definições da avaliação institucional conforme os seguintes autores:

[...] um processo de busca de compreensão da realidade escolar, com o fim de subsidiar a tomada de decisão quanto ao direcionamento das intervenções, visando ao aprimoramento do trabalho escolar. Como tal, a avaliação compreende a descrição, interpretação e o julgamento das ações desenvolvidas, resultando na definição de prioridades a serem implementadas e rumos a serem seguidos, tendo como referencia princípios e finalidades estabelecidos no projeto da escola, ao tempo em que subsidia a sua própria definição. (SOUSA, 1995, p.63)

A avaliação institucional da escola consiste em um processo sistemático, abrangente e contínuo de observação, coleta e análise de dados, interpretação e julgamento da realidade e prática escolares, em seus desdobramentos e interações, tendo como objetivo contribuir para a melhoria contínua do trabalho educacional e seus resultados. (LUCK, 2012, p.39)

Ao tomar esses conceitos como referência, concebemos a avaliação institucional como um processo sem fim, contínuo, de busca constante na melhoria do ensino que pressupõe e exige predisposição a mudança, visando à escola como um todo, levando em consideração os olhares de seus agentes.

Acrescentamos ainda, a definição de Dias Sobrinho (2003, p.177) de que a "avaliação educacional é uma prática social orientada, sobretudo, para produzir questionamentos e compreender os efeitos pedagógicos, éticos, sociais, econômicos do fenômeno educativo [...] ".

Desse modo, consideramos a avaliação institucional como um instrumento de potencialidade para a escola se apropriar da avaliação externa, conjugando-a com outros indicadores qualitativos que lhe permitam "olhar para si mesma", exercer sua autonomia, resgatando a finalidade da escola e não sendo "arrastada" e ficando a mercê apenas dos indicadores externos quantitativos. Mas também buscando compreender o que os mesmos estão indicando, indispensáveis para a tomada de decisões.

A partir de nossas colocações, vislumbramos a potencialidade da avaliação institucional, embora conscientes de seus limites e que sua elaboração coletiva seja uma tarefa complexa.

Grochoska (2013), em seu estudo sobre o processo de autoavaliação institucional desenvolvido numa escola de educação básica da região metropolitana de Curitiba-PR, afirma que ao final (ou seria início?) desse processo, o aspecto a ser levantado é a inclusão da autoavaliação institucional no Projeto Político-Pedagógico e no Regimento da Instituição. Muitas escolas até contemplam esse item em seus documentos ou encaminhamentos; no entanto, percebe-se que ainda são poucas as instituições que, de fato, concretizam essa prática de forma emancipatória para a tomada de decisão e melhoria do espaço escolar. (GROCHOSKA, 2013, p.109)

Esta informação da autora é também apontada por Freitas et al. (2012) que relata em pesquisa recente convidaram duzentos e cinquenta escolas para participar do esforço coletivo de desenvolvimento de avaliação institucional e apenas dez escolas se apresentaram.

Entretanto, apesar das pesquisas apontarem um número considerável de escolas que elaboram a avaliação institucional buscando apenas atender as exigências burocráticas; julgamos que a sua elaboração é indispensável como instrumento para viabilizar a aprendizagem dos alunos. 
Consideramos que deve a mesma deva ser buscada pelos gestores, não meramente para atender à legislação, mas porque a avaliação institucional é fundamental e necessária para atingir os objetivos educacionais.

Portanto, a avaliação institucional, pode ter também um papel de mediação entre a avaliação de sistema e a avaliação da aprendizagem. Identificamos a necessidade da avaliação institucional, ou seja, o coletivo da escola, analisar os resultados da avaliação de sistema, debruçar-se sobre estes dados, validá-los e encontrar formas de encaminhamento ao professor, de modo a oferecer subsídios à avaliação em sala de aula.

\section{RESULTADOS}

O foco neste estudo é o resultado do SARESP de 2016, dos anos finais do ensino fundamental disponibilizados pelo Boletim Pedagógico do SARESP 2016, de quatro escolas estaduais de uma cidade da região oeste do Estado.

O Boletim Pedagógico apresenta os pontos da escala de proficiência do SARESP agrupados em quatro níveis de proficiência - abaixo do básico, básico, adequado e avançado.

O nível abaixo do básico é classificado como insuficiente e indica que os alunos demonstram domínio insuficiente de conteúdos, das competências e das habilidades desejáveis para o ano/série escolar em que se encontram.

O nível básico é classificado como suficiente e indica que os alunos demonstram dpmínio mínimo dos conteúdos, das competências e das habilidades, mas que possuem as estruturas necessárias para interagir com a proposta curricular no ano/série subsequente.

O nível adequado é classificado como suficiente e indica que os alunos demonstram domínio pleno dos conteúdos, das competências e habilidades desejáveis para o ano/série escolar em que se encontram.

O nível avançado é classificado como avançado e indica que os alunos demonstram conhecimentos e domínio de conteúdos, das competências e habilidades acima do requerido para o ano/série escolar em que se encontram.

Torna-se necessário essas definições, pois de acordo com o nível de proficiência, o Boletim Pedagógico vai orientar a medida a ser tomada como encaminhamento pedagógico.

\begin{tabular}{l}
\multicolumn{3}{l}{ Níveis de proficiência - Medida a ser tomada } \\
1. Abaixo do Básico \\
$\begin{array}{lll}\text { 2. } & \text { Résico } & \text { Recuperação Intensiva } \\
\text { 3. Adequado } & - & \text { Recuperação Continuada } \\
\text { 4. Avançado } & - & \text { Aprofundamento } \\
\end{array}$
\end{tabular}

Cabe também, apresentar a Escala de desempenho do 9o ano no Ensino Fundamental (de 0 a 400 pontos) para Língua Portuguesa e Matemática foram as seguintes:

Abaixo do básico

Língua Portuguesa

Matemática

Básico

$<200$

$<225$

Adequado

$200 a<275$

225 a $<300$

Avançado

275 a $<325$

$300 \mathrm{a}<350$

$>=325$

$>=350$

Após estas considerações preliminares, apresentamos que na escola 1, participaram 88 alunos do 9 o ano do ensino fundamental do SARESP 2016. A média do desempenho em Língua Portuguesa foi 217,7 e em Matemática 247,5. Na escola 2, participaram 45 alunos do 9o ano do Ensino Fundamental do SARESP 2016. A média do desempenho em Língua Portuguesa foi 203,9 e em Matemática 224,7. Na escola 3, participaram 15 alunos do 9o ano do Ensino Fundamental do 
SARESP 2016. A média do desempenho em Língua Portuguesa foi 261,1 e em Matemática 270,6. $\mathrm{Na}$ escola 4, participaram 58 alunos do 9o ano do ensino fundamental do SARESP 2016. A média do desempenho em Língua Portuguesa foi 227,7 e em Matemática 247,8.

Pelas médias observadas nas quatro escolas, identificamos que três delas possuem o nível de proficiência básico e apenas uma delas, a escola 2, ficou em matemática com o nível de proficiência abaixo do básico. A partir destes resultados, de acordo com o Boletim Pedagógico os encaminhamentos pedagógicos seriam recuperação continuada para três escolas e recuperação intensiva para uma delas.

O objetivo do Boletim Pedagógico do SARESP é permitir que a escola análise seu desempenho e com o apoio da Secretaria Estadual de Educação, melhorar a qualidade da aprendizagem dos seus alunos. Os resultados foram disponibilizados para as escolas no início de fevereiro de 2017. O planejamento anual ocorre no mês de fevereiro e o replanejamento no mês de julho.

A próxima etapa desta pesquisa verificará se os resultados foram discutidos e quais ações foram implementadas nas quatro escolas selecionadas. Será utilizada a análise documental (atas e avaliação institucional) e a coleta de dados (entrevistas com gestores e professores).

\section{CONSIDERAÇÕES FINAIS}

A necessidade de reflexão pelo coletivo da escola sobre os resultados da avaliação de sistema é abordada por Brooke e Cunha (2015). Os autores informam que as Secretarias de Educação tentam suprir esta lacuna emitindo materiais informativos que tentam traçar um diagnóstico do nível de aprendizagem dos alunos. Os autores destacam dois materiais: Boletins Pedagógicos e Relatórios.

Outras pesquisas recentes apontam este direcionamento da avaliação para o apoio pedagógico (SOARES, 2015; SANTOS, CIASCA, 2015; ARAÚJO E OLIVEIRA, SILVA, 2015; BARRETO, 2015; BAUER, 2015; SILVA, NUNES, 2015).

Brooke; Cunha (2015) informam ainda que mesmo com a evolução da qualidade dos Boletins Pedagógicos e em alguns casos, a criação de um dia específico para estudo coletivo do material devolutivo pela escola, "a divulgação dos resultados não redunda automaticamente na sua apropriação por parte dos professores". (BROOKE; CUNHA, 2015, p.360)

Diante do exposto, consideramos um desafio, a reflexão dos resultados da avaliação de sistema pelos atores da escola em sua avaliação institucional objetivando a apropriação dos mesmos como subsídios aos professores em sala de aula. Este processo contribuiria para, a partir da análise aprofundada dos Boletins Pedagógicos, elaborar um diagnóstico e reorganizar as atividades, reorientar ações e rever os instrumentos utilizados na avaliação da aprendizagem.

Focamos neste estudo a análise dos resultados do SARESP na avaliação institucional realizada pelas escolas. No entanto, sabemos da necessidade de outros indicadores qualitativos elencados pelo coletivo que contribua para o resgate da finalidade da escola, ou seja, que a avaliação institucional, propicie a reflexão "para além dos conteúdos", buscando o desenvolvimento de valores, de consciência dos direitos e deveres, e da emancipação e autonomia dos sujeitos.

\section{REFERÊNCIAS}

ARAÚJO E OLIVEIRA, J.B.; SILVA, L.C. Para que servem os Testes de Alfabetização. In: BROOKE, N.; ALVES, M.T.G.; OLIVEIRA, L.K.M. (orgs.) A Avaliação da Educação Básica: a experiência brasileira. Belo Horizonte: Fino Traço, 2015, p.365-374. 
BARRETO, E.S.S. Políticas de Currículo e Avaliação e Políticas Docentes. In: BROOKE, N.; ALVES, M.T.G.; OLIVEIRA, L.K.M. (orgs.) A Avaliação da Educação Básica: a experiência brasileira. Belo Horizonte: Fino Traço, 2015, p.375-380.

BAUER, A. Uso dos Resultados do SARESP e Formação de Professores: a visão dos níveis centrais. In: BROOKE, N.; ALVES, M.T.G.; OLIVEIRA, L.K.M. (orgs.) A Avaliação da Educação Básica: a experiência brasileira. Belo Horizonte: Fino Traço, 2015, p.381-386.

BONAMINO, A; SOUSA, S. Z. Três gerações de avaliação da educação básica no Brasil: interfaces com o currículo da/na escola. Educação e Pesquisa. São Paulo: v. 38, n.2, p. 373-388, abr./jun. 2012.

BROOKE, N.; CUNHA, M.A de A. A Avaliação Externa como Instrumento da Gestão Educacional nos Estados. In: BROOKE, N.; ALVES, M.T.G.; OLIVEIRA, L.K.M. (orgs.) A Avaliação da Educação Básica: a experiência brasileira. Belo Horizonte: Fino Traço, 2015, p.359-364.

DIAS SOBRINHO, J. Avaliação institucional: teoria e prática. São Paulo: Cortez, 2003.

FREITAS, L.C. et al. Avaliação Educacional - caminhando na contramão. Petrópolis: Editora Vozes, 4.ed., 2012.

GROCHOSKA, M.A. As contribuições da autovaliação institucional para a escola de educação básica. Petrópolis: Vozes, 2013.

LUCK, H. Perspectivas da Avaliação Institucional da Escola. Campinas: Vozes, 2013;

SANTOS, F.D.G.; CIASCA, M.I.F.L. A Perspectiva do Acompanhamento Longitudinal da Aprendizagem dos Alunos do Ensino Médio através dos Resultados do SPAECE. In: BROOKE, N.; ALVES, M.T.G.; OLIVEIRA, L.K.M. (orgs.) A Avaliação da Educação Básica: a experiência brasileira. Belo Horizonte: Fino Traço, 2015, p.350-353.

São Paulo. SEE. Resolução SE n.27, de 29 de março de 1996. Dispõe sobre o Sistema de Avaliação de Rendimento Escolar do Estado de São Paulo. Disponível em:

http://siau.edunet.sp.gov.br/ItemLise/arquivos/27 1996.htm Acesso em: 20/07/2017.

. SEE. Boletim Pedagógico do SARESP de 2016. Disponível em:

http://saresp.fde.sp.gov.br/2016/ Acesso em 20.07.2017.

SILVA, V.A. da; NUNES, S. do C. Plano de Intervenção Pedagógica: resultados e perspectivas sob o olhar da inspeção escolar. In: BROOKE, N.; ALVES, M.T.G.; OLIVEIRA, L.K.M. (orgs.) A Avaliação da Educação Básica: a experiência brasileira. Belo Horizonte: Fino Traço, 2015, p.387-395.

SOARES, S. Avaliação Educacional como Instrumento Pedagógico. In: BROOKE, N.; ALVES, M.T.G.; OLIVEIRA, L.K.M. (orgs.) A Avaliação da Educação Básica: a experiência brasileira. Belo Horizonte: Fino Traço, 2015, p.350-353.

SOUSA. S. Z. Avaliação escolar: constatações e perspectivas. Revista de Educação AEC, Brasília: AEC do Brasil, ano 24, n.94, p. 59-66, jan./mar. 1995. 
VEIGA, I. P. A. Perspectivas para Reflexão em Torno do Projeto político Pedagógico. In: VEIGA, I. P. A; RESENDE, L.M.G. (Orgs). Escola: Espaço do projeto-político pedagógico. Campinas: Papirus, 1998, p.9-32.

WERLE, F. O. C. (org.) Avaliação em Larga escala foco na escola. São Leopoldo: Oikos Editora; Brasília: Líber Livro, 2010. 